\title{
LA ZONA ARQUEOLÓGICA DE LA GARMA (CANTABRIA): INVESTIGACIÓN, CONSERVACIÓN Y USO SOCIAL
}

\author{
THE ARCHAEOLOGICAL DISTRICT OF LA GARMA (CANTABRIA): RESEARCH, \\ CONSERVATION AND SOCIAL USE
}

PABLO ARIAS CABAL $(*)$

CÉSAR GONZÁLEZ SAINZ (*)

ALFONSO MOURE ROMANILLO (*)

ROBERTO ONTAÑÓN PEREDO $(*)$

\section{RESUMEN}

Se ofrece un panorama del proyecto de investigación que se está desarrollando desde 1996 para el estudio, conservación y puesta en valor del ComplejoArqueológico de La Garma. Se incide especialmente en los complejos problemas que conlleva la conservación de los restos arqueológicos superficiales y el conjunto de arte rupestre de la Galería Inferior, y las actuaciones desarrolladas al respecto. Finalmente, se valora la situación de la Zona Arqueológica de La Garma en relación con el contexto socioeconómico regional, y se exploran sus potencialidades y limitaciones como sitio de uso y disfrute social.

\begin{abstract}
This paper presents a general account of a research project that has been carried on since 1996 for the investigation, preservation and social use of the Archaeological District of La Garma (Cantabria, Spain). Special emphasis is placed on the problems involved in the conservation of the surface archaeological remains and the Palaeolithic rock art of the Galeria Inferior. Subsequently, the role of La Garma inside its local socio-economic context is evaluated. Finally, the possibilities and limitations of public use of the La Garma area are also discussed.
\end{abstract}

Palabras clave: Paleolítico. Magdaleniense. Mesolítico. Calcolítico. Edad del Bronce. Arte rupestre. Suelos de ocu-

(*) Dpto. de Ciencias Históricas. Universidad de Cantabria. Av. de los Castros s/n. 39005 Santander. pablo.arias@unican.es gonzalec@unican.es mourea@unican.es roberto.ontanon@ unican.es http://grupos.unican.es/prehistoria

El artículo fue remitido en su versión final el 19-IX-2000. pación. Castros. Arqueología pública. Gestión del Patrimonio. Conservación del Patrimonio.

Key words: Palaeolithic. Magdalenian. Mesolithic. Chalcolithic. Bronze Age. Rock Art. Floors. Hillforts. PublicArchaeology. Protection of the Archaeological Heritage. Cantabrian region. Northern Spain.

\section{LAS INVESTIGACIONES EN LA ZONA ARQUEOLÓGICA DE LA GARMA (1995- 1999)}

La Garma (Omoño, Ribamontán al Monte, Cantabria) es una pequeña elevación de $186 \mathrm{~m}$ de altitud, situada a unos $5 \mathrm{~km}$ de la desembocadura del río Miera en la parte oriental de la bahía de Santander (Fig. 1). Esta colina atesora uno de los conjuntos arqueológicos más espectaculares de la Prehistoria europea, tanto por la relevancia de algunos de sus componentes (en particular la Galería Inferior, con su impresionante yacimiento paleolítico en superficie), como por la inusualmente amplia y completa secuencia de ocupaciones documentada, que abarca desde el Paleolítico Inferior a la Edad Media.

Aunque algunos yacimientos del monte de $\mathrm{La}$ Garma (las cuevas del Truchiro y el Mar) eran conocidos desde hace casi un siglo (Sierra, 1909), el descubrimiento de la parte fundamental de este conjunto arqueológico es muy reciente. En 1991 se localizaron casualmente dos yacimientos en cueva, entonces juzgados de limitado interés, La GarmaA y La Garma B. Fue durante las excavaciones emprendidas en esas cuevas por un equipo del Depar- 

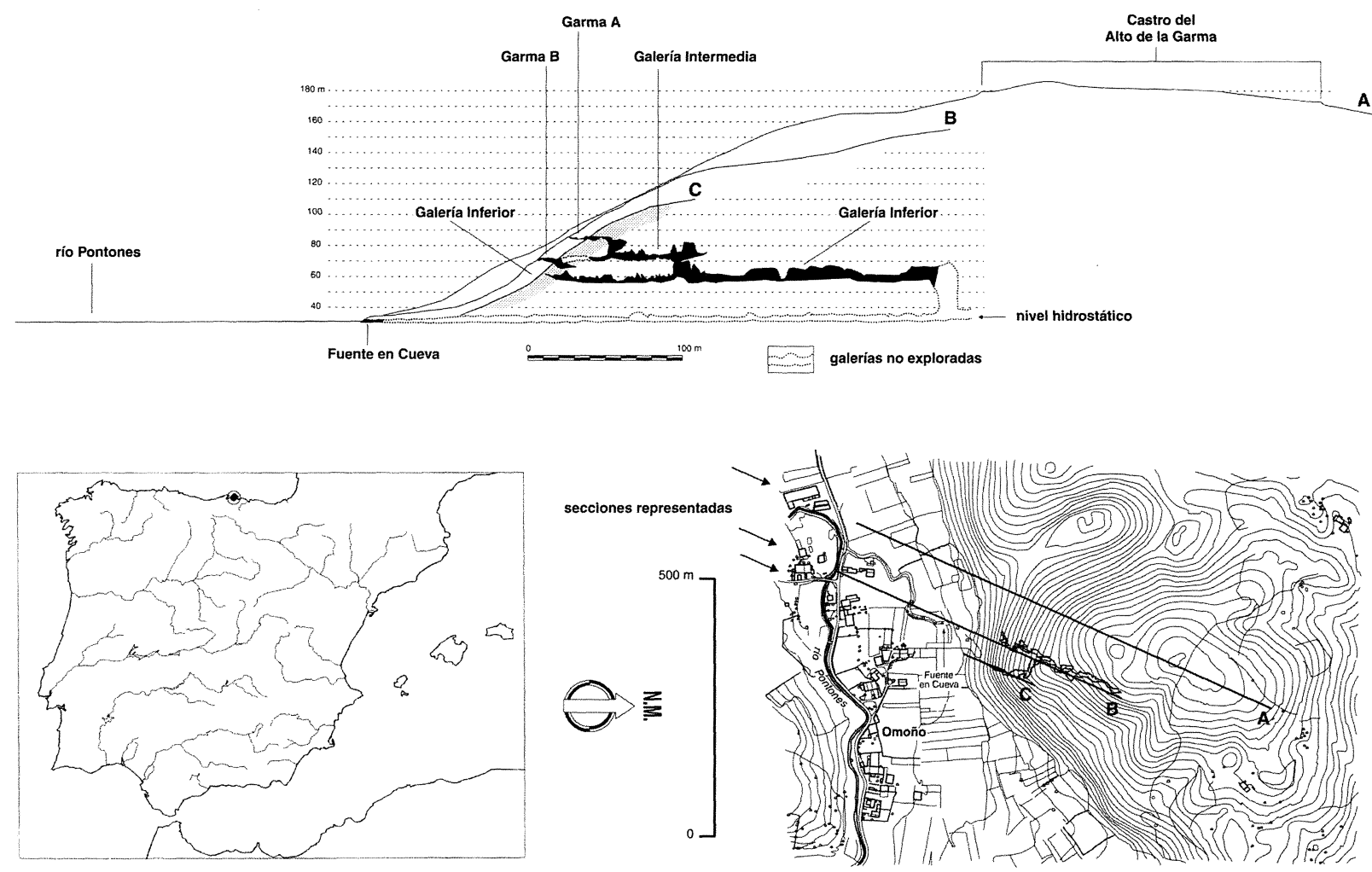

Fig. 1. Localización y sección del monte de la Garma (Cantabria), con la situación de los principales yacimientos.

tamento de Ciencias Históricas de la Universidad de Cantabria cuando se exploró la Galería Inferior, en la que, el 2 de noviembre de 1995, se descubrió un impresionante conjunto de yacimientos y manifestaciones de arte rupestre del Paleolítico Superior. A partir de este descubrimiento se puso en marcha un ambicioso proyecto de investigación, en el curso del cual se localizaron nuevos yacimientos (cuevas de Peredo, Valladar, La Garma C, La Garma D, castro del Alto de la Garma). Examinaremos ahora, de forma sucinta, los contenidos y características de esos sitios.

Los principales yacimientos se localizan en la vertiente meridional del monte de La Garma, en diversas cavidades de un amplio sistema cárstico (Fig. 1; Lám. I):

La Garma A. Cueva de corto desarrollo abierta a $84 \mathrm{~m}$ de altitud, que finaliza abruptamente en una sima vertical que comunica con la Galería Intermedia. Las excavaciones practicadas entre 1995 y 1999 han permitido documentar un depósito de unos $4 \mathrm{~m}$ de potencia, que se inicia en el Paleolítico Inferior (excavado en el exterior de la cueva, donde el retro- ceso de la visera del abrigo ha dejado la base de la estratigrafía al aire libre) e incluye diversos estratos del Paleolítico Superior, un conchero mesolítico, indicios neolíticos, estructuras y estratos sepulcrales del Calcolítico y Edad del Bronce y algunos restos medievales en superficie.

La Garma B. Es una pequeña cavidad fosilizada que apenas alcanza los $30 \mathrm{~m}$ de longitud, abierta a $71 \mathrm{~m}$ sobre el nivel del mar. Excavada en tres campañas en 1995 y 1996, ha ofrecido fundamentalmente enterramientos del Calcolítico y la Edad del Bronce.

Galería Intermedia. Se trata de un segmento del mismo piso del sistema que La Garma B, de la que está separada unos $15 \mathrm{~m}$ por reconstrucciones estalagmíticas. Actualmente se accede descendiendo una sima de $7 \mathrm{~m}$ de altura desde La Garma A. En superficie se han encontrado numerosas oseras, que alteran superficialmente un potente estrato con industrias del Paleolítico antiguo, sondeado en 1999. Al final de la galería se han localizado series de puntos pintados en rojo atribuibles al Paleolítico 


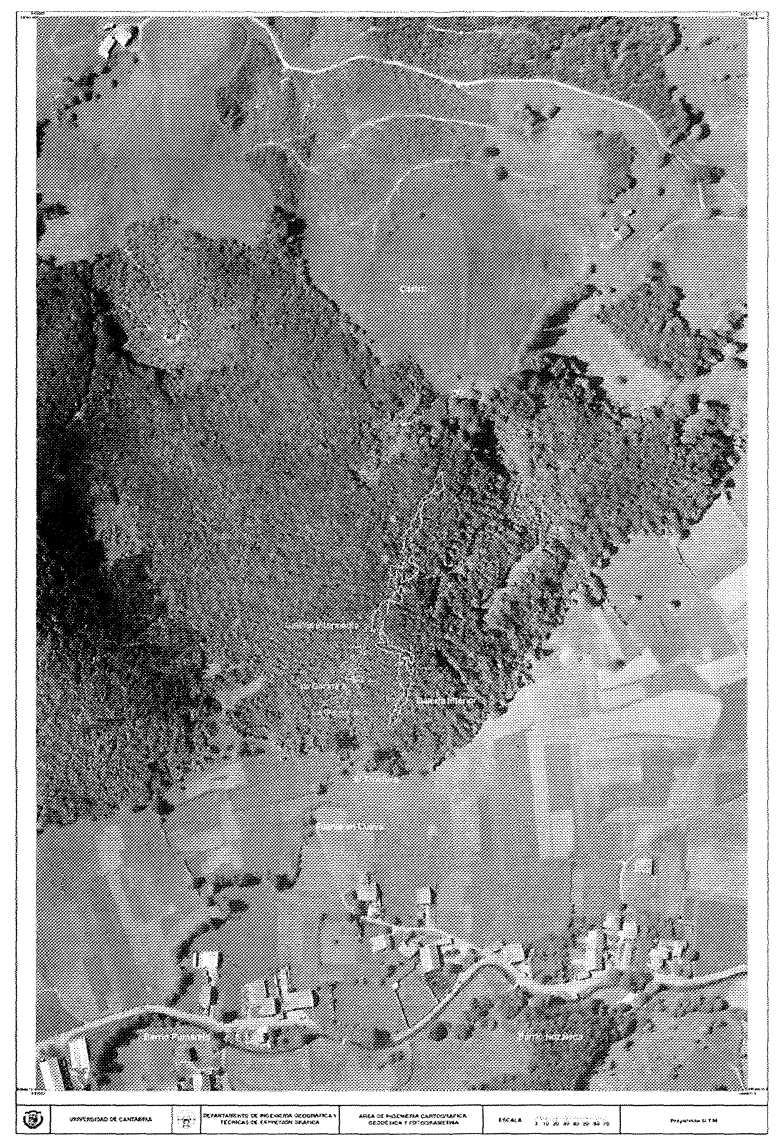

Lám. I. Ortofotografía de La Garma (Cantabria), con indicación de la situación de las principales galerías del sistema cárstico. Obsérvense las defensas del castro.

Superior, así como carbones y una hoguera datados en la Alta Edad Media.

Galería Inferior. Galería de unos $300 \mathrm{~m}$ de desarrollo, situada entre 58 y $55 \mathrm{~m}$ de altitud, cuya entrada original quedó bloqueada por un derrumbe al final del Paleolítico Superior. Actualmente se accede desde la Galería Intermedia, descendiendo una sima de $13 \mathrm{~m}$ de altura. A esta cavidad corresponden los hallazgos más relevantes de todo el Complejo. En la superficie de los primeros $70 \mathrm{~m}$ de la Galería se extiende un yacimiento magdaleniense de más de $500 \mathrm{~m}^{2}$, con abundantes evidencias de estructuras -cabañas, hoyos, amontonamientos de huesos etc. $-\mathrm{y}$ miles de restos de fauna e industria lítica y ósea (Lám. II). En las paredes contiguas, se observan numerosos lienzos con arte rupestre paleolítico, de los que por el momento son accesibles únicamente los correspondientes a zonas de suelo cubiertas por planchas estalagmíticas. Existen otras dos importantes concentraciones de restos paleolíticos en superficie en dos áreas más interiores, a 90 y 130 m de la entrada original, donde también se han encontrado estructuras delimitadas por muretes de piedra seca adosados a las paredes. Además, a lo largo de toda la cueva se encuentran restos dispersos de la presencia de los grupos paleolíticos y numerosas pinturas y grabados rupestres.

Los yacimientos de superficie parecen corresponder al Magdaleniense Medio, a juzgar por las industrias, piezas de arte mobiliar y fauna observados hasta ahora, coherentes, además, con las fechas de radiocarbono obtenidas (1). Por su parte, en el amplio conjunto de arte rupestre (2) se han podido diferenciar al menos tres fases: una del Paleolítico Superior inicial (manos en negativo, trazos pareados, series de trazos y puntos, quizá algunos animales en rojo); otra atribuible al Solutrense o el Gravetiense (pinturas rojas de animales, signos cuadriláteros, algunos grabados), y una tercera de cronología magdaleniense, con predominio de pintura negra y gran cantidad de grabados.

Con posterioridad al cierre de su entrada, la Galería Inferior fue visitada hacia el siglo VIII d.C.A esta época corresponden los restos de cuatro personas depositados en el suelo de la Galería, y un buen número de carbones y marcas en las paredes distribuidos por casi todo su recorrido.

Cueva del Mar. Cueva con una amplia boca situada en la parte oriental del monte de La Garma. Se conservan restos cementados de un conchero mesolítico, que fue sondeado en 1999.

Castro delAlto de La Garma. Recinto amurallado de forma ovalada y unos $18000 \mathrm{~m}^{2}$, situado en la cima de la colina (Lám. I). Las excavaciones desarrolladas hasta 1999 han permitido localizar varias fases de ocupación del poblado y de construcción de las fortificaciones. Todas ellas se pueden atribuir a fases relativamente antiguas de la Edad del Hierro o incluso al Bronce Final.

Otros yacimientos: En diversas covachas de la vertiente meridional de La Garma (El Truchiro, Valladar, Peredo, La Garma C, La Garma D) se han

(1) OxA-8721: $14050 \pm 110$ BP y OxA-8722: $13610 \pm 100 \mathrm{BP}$

(2) A falta de algunos paneles de grabados por explorar, incluye 511 unidades gráficas, entre ellas 89 figuras animales, 3 máscaras, 41 manos en negativo, 26 signos complejos, 40 series de trazos pareados y 35 composiciones con puntos. 


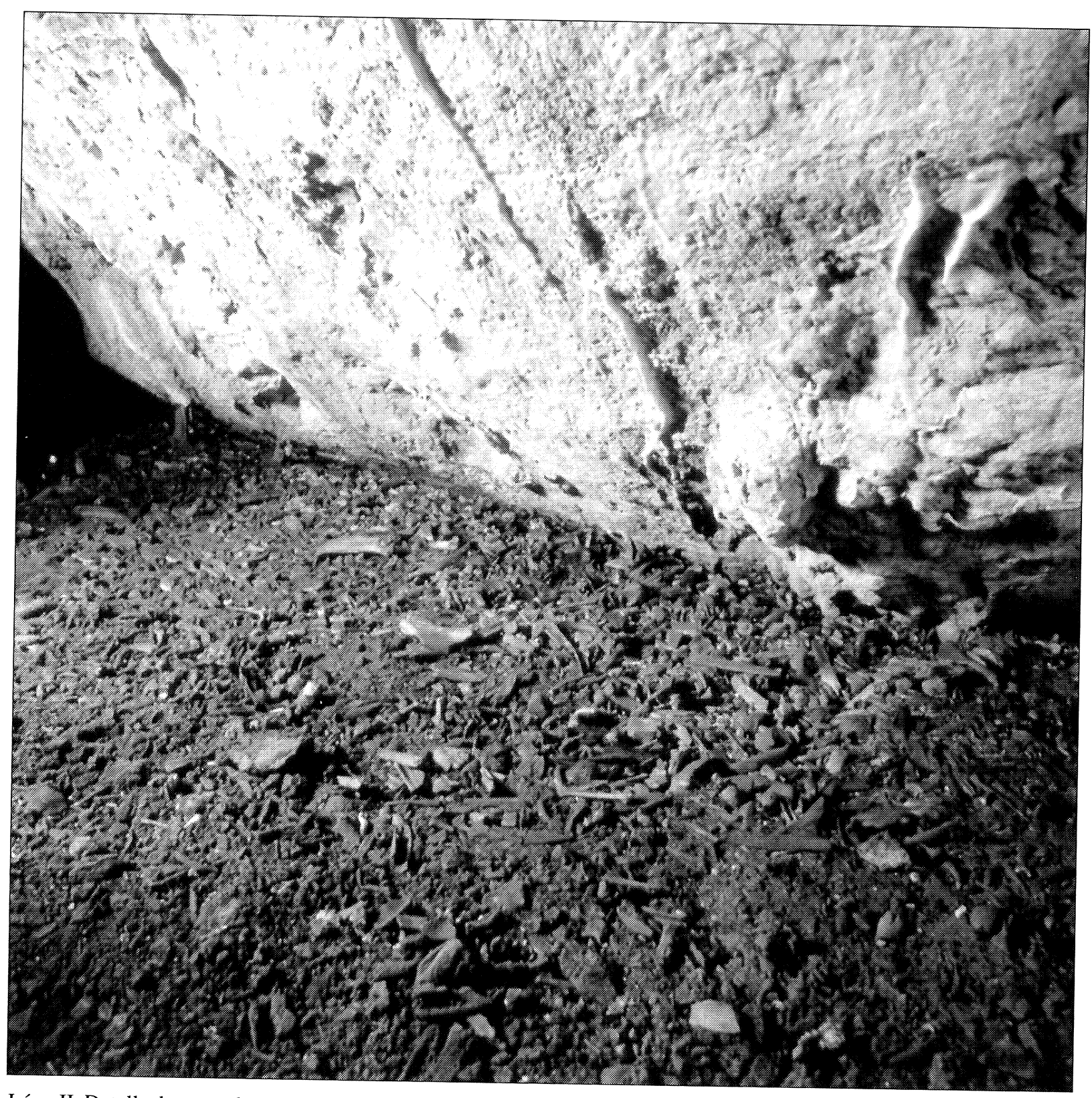

Lám. II. Detalle de un suelo magdaleniense de la Galería Inferior de La Garma (Cantabria). Foto Pedro Saura.

localizado restos arqueológicos del Calcolítico, la Edad del Bronce y la Edad Media, por lo general asociados a sepulturas.

Las magníficas oportunidades de investigación de la Galería Inferior y, al tiempo, la dificultad de acceder a ella sin causar un deterioro irreversible en su preservación, ha incidido en la articulación de un proyecto de investigación en torno a dos principios básicos:
- un estudio arqueológico orientado tanto al análisis exhaustivo de las ocupaciones humanas en el monte de La Garma como al estudio, a través de este conjunto de yacimientos, de la evolución de las sociedades del sector central de la región cantábrica desde el Paleolítico Inferior a laAlta Edad Media.

- una investigación encaminada a determinar las condiciones microambientales que han hecho posible la conservación del conjunto arqueológico, 
y a establecer unas pautas de intervención que garanticen su preservación para investigaciones futuras y para un uso social directo de determinados sectores del Complejo.

Esto se ha materializado en un programa plurianual de investigación denominado "Estudio integral del Complejo Arqueológico de La Garma", que se ha venido desarrollando desde 1996. En él colaboran más de dos decenas de especialistas de materias como Prehistoria, Arqueología, Ingeniería Geográfica, Paleontología, Geología, Geomorfología, Sedimentología, Antropología Física, Paleobotánica y Microbiología, pertenecientes a diferentes centros de investigación (universidades, museos y Consejo Superior de Investigaciones Científicas). Los análisis (Carbono 14, Termoluminiscencia, Uranio/Thorio, análisis de pigmentos, etc.) y las actuaciones de restauración se llevan a cabo en distintos laboratorios especializados de Europa y América. La financiación del proyecto ha corrido a cargo, en su mayor parte, de la Consejería de Cultura y Deporte del Gobierno de Cantabria (a través de convenios anuales de este organismo con la Universidad de Cantabria), que ha apoyado decididamente las investigaciones de $\mathrm{La}$ Garma, las cuales han constituido un elemento fundamental de su política arqueológica durante estos últimos años.

Hemos de poner de relieve que la gran trascendencia que ha tenido el descubrimiento de La Garma (principalmente en Cantabria, pero también fuera de la región) hace que este proyecto no se pueda limitar a una investigación académica convencional. Como expondremos más abajo, el proyecto debe conjugar el objetivo, fundamental en cualquier investigación arqueológica, del conocimiento del pasado, con una marcada orientación al trabajo en la conservación del Patrimonio, así como un desarrollo coherente de su gestión y puesta en valor, y una estrategia acerca de la manera en que el conocimiento generado se presenta al público, algo que, como señala P. McManamon (2000: 6) es demasiado importante para los arqueólogos para que los dejemos en manos de otros. Es decir, el proyecto, de fuerza o de grado, ha de penetrar decididamente en el proceloso campo de lo que últimamente se ha dado en llamar "Arqueología pública" (Schadla-Hall, 1999) y sustituir el concepto un tanto restrictivo de mera "protección del monumento" por el más amplio y complejo de "gestión del Patrimonio" (Cleere, 1984; Willems, 1998).

\section{EL RETO DE LA CONSERVACIÓN DE LA GARMA}

Si la conservación es uno de los problemas fundamentales que se plantean en relación con cualquier sitio arqueológico -y en general con cualquier bien del Patrimonio Histórico-, en el caso de La Garma es una cuestión central. El excepcional estado de conservación de la Galería Inferior, sin duda uno de los conjuntos mejor preservados de todo el Paleolítico mundial, hace que se deban extremar las precauciones para evitar una degradación de tan singular yacimiento. De hecho, desde nuestra primera visita, los responsables del proyecto hemos afrontado una enorme responsabilidad: la obligación de legar a las futuras generaciones ese extraordinario conjunto en un estado lo más cercano posible al que tenía el 2 de noviembre de 1995. Por ello, todo el planteamiento del proyecto de investigación que se está desarrollando en La Garma se articula en torno a lá idea de primar la conservación por encima de cualquier otro objetivo.

Ahora bien, ¿qué se entiende por conservación en un conjunto como éste? Es evidente que mantenerlo estrictamente en el estado original, sin la más mínima alteración, habría sido imposible, salvo que se hubiera optado por clausurar la cueva al día siguiente de la primera exploración. No obstante, en un conjunto de las características de La Garma esta última posibilidad tiene poco sentido, pues sin una exploración digna de tal nombre era imposible hacerse una mínima idea del contenido arqueológico de la Galería Inferior. De esta manera, aunque el cierre de la cueva habría asegurado su conservación en un estado muy cercano al original, también habría impedido el conocimiento de los bienes a conservar. Nuestra opinión es que, en este caso, la “opción del candado" por sí sola es absurda. La mera conservación pasiva es cuestionable desde el punto de vista científico, y es muy difícil de justificar desde la perspectiva social. Conservación e investigación son dos aspectos indisociables, pues, aunque es evidente que hay que conservar el Patrimonio para poderlo investigar (ahora y en el futuro), no es menos cierto que tiene escaso sentido conservar algo que no se conoce y no puede ser puesto a disposición de la sociedad.

Nuestro planteamiento se ha basado, por lo tanto, en dos principios: en primer lugar, hemos intentado realizar una intervención arqueológica poco agresiva, que se limitara a lo estrictamente necesario para documentar adecuadamente el contenido de 
la Galería Inferior y que, donde se pudiera, fuera reversible. En segundo lugar, la parte fundamental de esta intervención se debería realizar una vez que se hubieran controlado aceptablemente las condiciones ambientales de la Galería, y debería efectuarse documentando, en la medida de lo posible, los efectos de la intervención. A este respecto, hay que tener en cuenta que el propio carácter intacto de la Galería Inferior de La Garma abre interesantísimas perspectivas de investigación en una materia clave relacionada con la preservación del Patrimonio Histórico: las condiciones ambientales que hacen posible la conservación del arte rupestre en cuevas. Desde este punto de vista, la Galería Inferior puede convertirse en un verdadero laboratorio que permita avanzar sustancialmente en el estudio de esas condiciones, y de las medidas que se pueden arbitrar para asegurar su mantenimiento.

Obviamente, la viabilidad a medio plazo de los planteamientos que acabamos de exponer requiere que esté razonablemente garantizada la protección de los testimonios arqueológicos. Por fortuna, la acción de las autoridades competentes ha sido, a este respecto, modélica. Desde el mismo día en que se le notificó el descubrimiento, la Consejería de Cultura y Deporte del Gobierno de Cantabria tomó rápidas y eficaces medidas de control de los accesos a la cueva, y se tramitó con suma celeridad el expediente de declaración monumental

En lo que se refiere a este último aspecto, el conjunto de La Garma ha sido dotado con el máximo grado de protección legal previsto en la Ley de Patrimonio Histórico Español. Con fecha de 24 de julio de 1998, el ComplejoArqueológico de La Garma fue declarado Bien de Interés Cultural (BIC), con categoría de ZonaArqueológica (3). Es importante subrayar que la declaración como BIC no afecta únicamente a la parte más espectacular, la Galería Inferior (que ya era acreedora de esa calificación en virtud del art. 40.2 de la mencionada Ley, que concede tal categoría a todas las cuevas, abrigos y lugares que contengan manifestaciones de arte rupestre), sino a una superficie de $1020312 \mathrm{~m}^{2}$ que incluye todo el monte de La Garma y algunas zonas adyacentes (4). Con ello, se garantiza la pro-

(3) La declaración se realizó por el Decreto 64/1998 de 17 de julio de la Consejería de Cultura y Deporte, publicado en el Boletín Oficial de Cantabria el 23 de julio de 1998. Queremos poner de relieve que la incoación del expediente (que, como es sabido, en lo que se refiere a la protección tiene los mismos efectos que la propia declaración) se produjo inmediatamente después del descubrimiento, el 23 de noviembre de 1995.

(4) La zona protegida va desde la propia base de la colina de La Garma en su vertiente meridional (junto a las primeras casas tección legal y el control de todos los yacimientos, de su entorno natural y de algunas zonas próximas que podrían afectar a su conservación, como el área de captación de corrientes subterráneas que fluyen hacia el sistema cárstico. De esta manera, se ha superado en este caso la noción tradicional de protección de monumento aislado que, desgraciadamente, ha sido tan frecuente en España, y se abren magníficas perspectivas, tanto desde el punto de vista de la investigación arqueológica como de la futura puesta en valor y disfrute social de La Garma, que pasa indudablemente por tener en cuenta sus valores naturales y la gran variedad y amplitud temporal de sus testimonios arqueológicos, en los que se refleja la mayor parte de la Historia regional, desde el comienzo del poblamiento hasta el siglo XIII.

La decidida actitud proteccionista de la administración regional se manifestó de forma aun más palmaria en la actuación desarrollada con respecto al castro del Alto de La Garma. Este poblado fue reconocido en el verano de 1996, en el transcurso de la primera campaña de trabajo de campo que siguió al Convenio con el Gobierno regional. Desgraciadamente, la finca que ocupa la mayor parte del recinto fortificado había sido plantada de eucaliptos pocos meses antes. Por fortuna, los destrozos habían sido mínimos, pues únicamente se habían cavado pequeños hoyos para colocar los plantones de los árboles, sin construirse abancalamientos ni una densa red de pistas, como sucede en muchas explotaciones forestales (5). No obstante, el previsible crecimiento de las raíces ponía en serio peligro la conservación del castro. Por otro lado, la plantación estaba aproximadamente en la vertical del final de la Galería Inferior, con lo que no se podía excluir que su desarrollo pudiera afectar al régimen hidrológico del sistema, y con él a la conservación de las pinturas. Expusimos esta situación a la Consejería de Cultura y Deporte del Gobierno de Cantabria, la cual decidió abrir inmediatamente negociaciones con los propietarios para adquirir

del pueblo de Omoño) hasta el límite septentrional del municipio de Ribamontán al Monte, y desde la colina adyacente por el oeste (el monte Valladar) hasta la carretera comarcal S-411, que pasa por la collada que separa el monte de La Garma del pueblo de Liermo. Se han establecido dos grados de protección, un área directa de $667812 \mathrm{~m}^{2}$, y un entorno de protección de $352500 \mathrm{~m}^{2}$

(5) El diámetro de estos agujeros era de unos $30 \mathrm{~cm}$. Téngase en cuenta, por otra parte, que, según nos informaron los propietarios, la finca en cuestión era el producto de la roturación, hacia 1930, de un robledal. Es probable que las raíces de aquellos árboles y los trabajos de roturación hubieran alterado las capas superficiales del depósito arqueológico en un grado comparable, o incluso superior, a la plantación de 1996. 
la finca (6). Una vez completada la operación, se procedió a eliminar los eucaliptos. Con la adquisición de esta finca por el Gobierno regional, la mayor parte del monte de la Garma es de titularidad pública (7), con lo que no sólo se asegura su adecuada conservación, sino que se facilitan notablemente las posibilidades de puesta en valor del conjunto arqueológico.

Como ya hemos señalado más arriba, la parte más sensible del conjunto de La Garma fue objeto de protección física con la máxima celeridad, lo cual era, en este caso, de vital importancia para asegurar que la Galería Inferior se mantuviera totalmente aislada de actuaciones incontroladas. Afortunadamente, el único acceso practicable al interior del sistema cárstico, la boca de La Garma A, contaba ya con una verja instalada por la Consejería de Cultura y Deporte en 1991, cuando se descubrieron este yacimiento y La Garma B, donde también se colocó entonces un cierre. Esta rápida actuación de las autoridades de Patrimonio para proteger dos yacimientos aparentemente intactos, pero en los que nada permitía presagiar un interés excepcional, resultó ser de una importancia crucial, pues muy probablemente impidió alguna visita de la Galería Inferior por personal no especializado (8), que hubiera tenido nefastas consecuencias (probables daños en los yacimientos, imposibilidad de certificar la antigüedad de la localización de objetos en determinados lugares...). No obstante la existencia de esta verja, la Consejería de Cultura y Deporte quiso extremar al máximo la seguridad, por lo que se colocó una segunda puerta en el interior de La Garma A y se instaló una alarma en la entrada de esta cueva, conectada por radio con una central de seguridad (9). Asimismo, ha existido un control periódico de la zona por parte de la Guardia Civil. Por

(6) Es obligado agradecer la colaboración de los anteriores propietarios, D. Inocencio de la Vega Cagigal y sus hermanos D. Jacinto y D. ${ }^{a}$ Pilar, quienes nos permitieron continuar los trabajos arqueológicos en su propiedad durante el largo proceso administrativo que condujo a la compra del castro, y nos dieron todo tipo de facilidades.

(7) El resto pertenece en su mayor parte a la Junta Vecinal de Omoño, propietaria del bosque de encinas que cubre casi toda la ladera meridional de La Garma. Hay algunas parcelas privadas, destinadas a pradería o plantaciones de eucaliptos, pero en ningún caso afectan a los yacimientos arqueológicos.

(8) Durante los días transcurridos entre el descubrimiento de la cueva y la colocación de la verja se produjeron numerosas visitas de vecinos y curiosos, que incluso llegaron a descender a la Galería Intermedia, aunque no, afortunadamente, a la Galería Inferior.

(9) Desde el momento en que el descubrimiento trascendió a los medios de comunicación hasta que se instaló la alarma, la boca de la Garma A estuvo protegida día y noche por vigilantes. todo lo anterior, creemos que no es exagerado considerar La Garma como uno de los conjuntos arqueológicos mejor protegidos del país.

Pero todas estas medidas, aun siendo imprescindibles, serían insuficientes por sí solas. Para asaltantes verdaderamente decididos no hay verja imposible de forzar. Por ello, es fundamental la defensa que los propios ciudadanos pueden prestar al Patrimonio Histórico de su entorno. Por fortuna, en el caso de La Garma este aspecto de la protección parece estar particularmente bien cubierto. El grado de concienciación de los vecinos de Omoño es muy alto, a lo que, sin duda, ha contribuido de manera decisiva la gran relevancia que le han dado los medios de comunicación al conjunto arqueológico. Fomentar esa actitud ha sido para nosotros una preocupación constante. Con ese objetivo se han presentado públicamente en Omoño los resultados del proyecto, y se ha distribuido información de todas las actividades divulgativas desarrolladas en la región. Así mismo, numerosos grupos de personas de la localidad han realizado visitas guiadas de los trabajos de campo, e incluso se ha contado con la participación en las excavaciones de personas del municipio. Con todo ello, creemos que se ha conseguido implicar verdaderamente a los vecinos de Omoño en la defensa de La Garma, lo cual es sin duda la más eficaz protección posible, máxime en este caso, pues la cercanía al pueblo del acceso a la parte más sensible del conjunto (la boca de La Garma A), y su visibilidad desde algunos barrios, hacen que sea prácticamente imposible que un eventual saqueador pueda actuar en el lugar sin que los vecinos detecten su presencia.

Una vez que está razonablemente controlado el peligro exterior, el principal riesgo para el Complejo de La Garma viene, aunque parezca paradójico, de nosotros mismos, de los arqueólogos que estamos trabajando en los yacimientos. Pese a la buena voluntad y el exquisito cuidado de los que participan en las investigaciones, no cabe duda de que la mera circulación de personas por un ambiente tan frágil como la Galería Inferior es en sí misma un peligro. Conscientes de esta situación, hemos intentado extremar las medidas de seguridad para controlar los daños que nuestra actuación arqueológica pueda ocasionar.

La primera de esas medidas ha sido la propia limitación del acceso y los movimientos por el interior del sistema, en particular en la Galería Inferior. Se ha restringido la entrada a esta galería a las visitas imprescindibles justificadas por el desarrollo 
de los trabajos de topografía y documentación arqueológica, y siempre con equipos lo más reducidos que ha sido posible. En todo caso, se ha llevado un registro exhaustivo de todas las visitas que se han realizado. Para ello, se han confeccionado unos cuestionarios en los que se especifica el nombre de las personas que han entrado en la Galería Inferior, la finalidad de su visita, y se señala con precisión el recorrido seguido, así como el horario de entrada y salida del sistema y de paso por una serie de estaciones. Además de permitir un control de las visitas realizadas, este sistema es de gran utilidad para registrar la posible influencia de la presencia humana en el sistema (vid. infra). Se ha intentado también limitar al máximo la contaminación de la Galería Inferior con materiales procedentes del exterior. Por ello, como norma general, las personas que han descendido a ese piso de la cueva han cambiado el calzado embarrado que traían del exterior por otro con las suelas limpias. Por supuesto, no se introduce comida ni ninguna otra materia susceptible de favorecer la formación de colonias de microorganismos.

No obstante, aun siendo las visitas escasas, en grupos pequeños y con participación de personal especializado, sigue habiendo riesgo de destrucción involuntaria de indicios arqueológicos irreemplazables. Por ello, desde las primeras exploraciones se procedió a acotar el acceso a determinados tramos de la cueva (en particular las tres zonas con gran densidad de restos paleolíticos en superficie de las áreas I, III y IV) y a establecer un itinerario obligado. Eramos conscientes de que la circulación incontrolada, incluso de personal particularmente cuidadoso, podría conducir a la degradación por pisoteo de los testimonios arqueológicos. Por ello, se marcó un estrecho camino, de unos $50 \mathrm{~cm}$ de anchura media, con plaquitas de aluminio recubiertas por material reflectante. Estas placas son muy visibles al circular por la cueva, no plantean ningún problema de contaminación, y están simplemente posadas en el suelo, sin ninguna sujeción, por lo que no alteran la superficie del yacimiento, y se pueden retirar sin dificultad en caso de que se requiera.

Como señalábamos más arriba, el objetivo central que ha conformado toda la planificación de los trabajos desarrollados en La Garma ha sido hacer compatible el conocimiento científico de la Galería Inferior con la mejor conservación que fuera posible de tan singular espacio. Por ello, los criterios que han guiado las investigaciones han primado la conservación sobre la rápida documentación de las partes más espectaculares. De hecho, las limitaciones a la movilidad en la Galería Inferior hacen que todavía no contemos con un catálogo completo de las manifestaciones de arte rupestre (probablemente conozcamos la mayor parte de las pinturas, pero no los grabados de algunas zonas, por el peligro que supone acercarse a las paredes en muchos lugares) o de restos paleolíticos en los suelos. En realidad, la marcha de los trabajos se ha adaptado a los problemas específicos de conservación, y en el primer cuatrienio de investigaciones de campo nos hemos centrado en la documentación de otras partes menos comprometidas del sistema (La Garma A, La Garma B, Galería Intermedia, cueva del Mar, Alto de la Garma). En la Galería Inferior únicamente se ha realizado una primera aproximación, consistente en la elaboración de un inventario y análisis de los indicios localizados en partes con bajo riesgo, y en la planificación de los futuros trabajos en las zonas más comprometidas. Esta parte, que se prevé comenzar en el presente año, primará las técnicas no agresivas. Así, la documentación general de la distribución de los restos paleolíticos se realizará por medio de fotogrametría, fotografiando los suelos con una cámara métrica Rolleiflex 3003 y realizando la posterior restitución a través del programa informático Rolleimetric CDW, a partir del cual se efectúa un tratamiento de la imagen por medio de diversos programas.

Un serio problema que se ha planteado es la necesidad de moverse por las superficies tapizadas de restos arqueológicos. Aunque la técnica fotogramétrica empleada no requiere obtener fotografías verticales, en muchos casos es necesario aproximarse. Este es un problema común a muchos sitios de este género (Enlène, Chauvet...). En nuestro caso, estamos ensayando con un sistema de andamiaje a base de pasarelas ligeras desmontables, ancladas en bloques o en zonas de concreción estalagmítica, que permitan cierta movilidad por encima de las concentraciones de restos arqueológicos para realizar el levantamiento fotogramétrico y la identificación de los restos.

Un aspecto fundamental del proyecto de $\mathrm{La}$ Garma es la conservación del arte rupestre. Como en cualquier nuevo conjunto artístico, una de las principales responsabilidades de los encargados de su gestión ha de ser el mantenimiento de las pinturas y grabados en perfecto estado. Sin embargo, en el caso de La Garma, las circunstancias particulares del hallazgo abren nuevas e interesantes pers- 
pectivas. Al tratarse de una cueva completamente intacta, en la que ha habido un estricto control arqueológico desde el mismo día del descubrimiento, es posible establecer con la máxima precisión las condiciones ambientales que han facilitado la conservación de las manifestaciones artísticas durante milenios. Desde este punto de vista, sitios como La Garma, Chauvet y otros grandes conjuntos descubiertos en los últimos años ofrecen excelentes posibilidades que desgraciadamente ya no se encuentran en los grandes santuarios clásicos, tipo Altamira, Niaux, Lascaux, Candamo, Nerja, etc. En estos últimos lugares se han hecho grandes esfuerzos para acercarse a la reconstrucción de los parámetros que han permitido su conservación, y para establecer condiciones mínimas que aseguren el mantenimiento de las pinturas (VV.AA., 1983 y 1984, Fortea, 1993; Brunet et alii, 1990; Brunet y Vouvé, 1996; Romero, 1997). Sin embargo, las importantes transformaciones que han sufrido dichas cuevas al acondicionarlas para la visita turística hacen muy difícil, por no decir imposible, conocer con exactitud el punto de partida del sistema. En cuevas como La Garma, por el contrario, esto es más factible: esas condiciones se siguen dando todavía, y únicamente hay que realizar un seguimiento durante un tiempo suficiente para determinar cuáles son los valores en los que nos debemos mantener para garantizar una larga conservación de las pinturas. Por otra parte, a partir de este tipo de investigaciones se irá obteniendo información sobre condiciones de preservación de las cuevas con arte rupestre que pueden ser de gran utilidad para establecer modelos de conservación y gestión sostenible de las cuevas que están abiertas al público.

Los trabajos de control ambiental se iniciaron desde los propios días que siguieron al descubrimiento, bajo la dirección de uno de los más reputados especialistas españoles en la materia, el Dr. Manuel Hoyos (10). Entre las primeras medidas que se tomaron destaca la instalación en distintos puntos de la cueva de aparatos de registro automático para la medición continua de las variables ambientales más relevantes -temperatura, humedad relativa y concentración de $\mathrm{CO}_{2}$-. Estas sondas se han colocado en tres lugares en los que existían

(10) El fallecimiento de nuestro querido compañero Manolo Hoyos en la primavera de 1999 dejó este trabajo, que se había desarrollado hasta ese momento bajo su coordinación, inconcluso, aunque hemos continuado la investigación a partir de sus directrices. Quede constancia una vez más de nuestro profundo pesar por tan sensible pérdida, tanto en el plano científico como, sobre todo, en el humano.

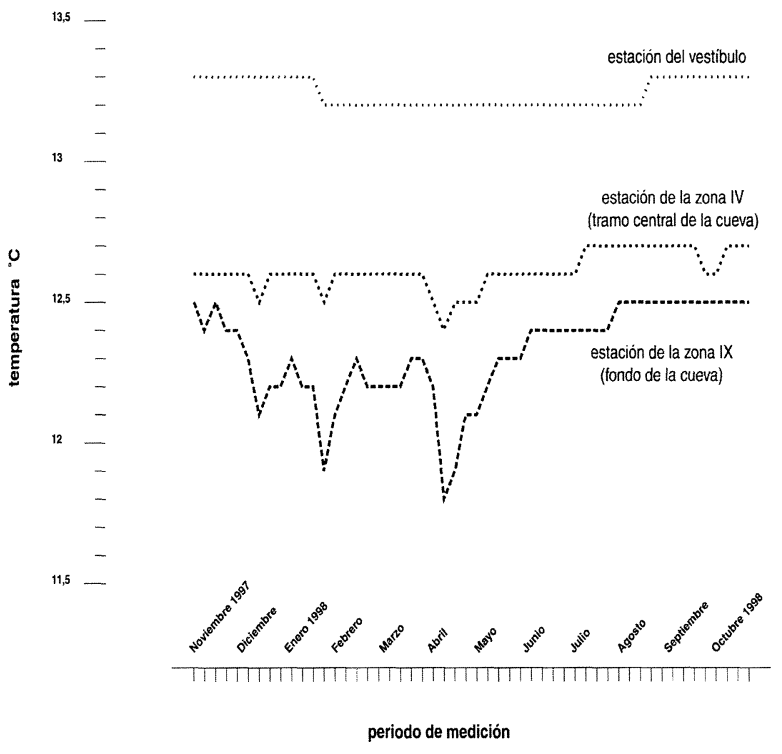

Fig. 2. Evolución de las temperaturas en la Galería Inferior de La Garma (Cantabria) durante un año.

condiciones a priori diversas, en función de su relación con la circulación del aire en la cueva: la zona I, a unos $25 \mathrm{~m}$ de la entrada original (11), la zona IV, junto al pozo de comunicación con la Galería Intermedia, y la zona IX, al final de la Galería Inferior, al lado de la sima que desciende al nivel hidrostático. Las medidas se toman automáticamente cada hora (a la hora en punto), y se registran en dataloggers con capacidad para almacenar unas 10000 medidas), lo que permite mantener el sistema en funcionamiento de forma autónoma durante más de trece meses. Periódicamente los datos se descargan en un ordenador portátil. Estos resultados, por otro lado, se pueden cotejar fácilmente con la información disponible acerca de la circulación de personas por la cueva para los trabajos de investigación, gracias a las fichas mencionadas más arriba, en las que se indica la hora en que pasan los investigadores junto a cada una de las sondas, y el tiempo de permanencia. De esta manera, podremos evaluar a partir de datos objetivos el impacto de la presencia humana en la cueva y, a partir de aquí, diseñar una estrategia de trabajo para la conservación de las pinturas en ésta o en otras cavidades que tengan establecido un régimen de visitas públicas.

(11) La sonda se instaló en el lugar más cercano a la entrada al que se podía acceder con facilidad. Colocarla más cerca hubiera obligado, para recoger los datos, a pasar por zonas en las que hemos restringido el acceso por problemas de conservación. 


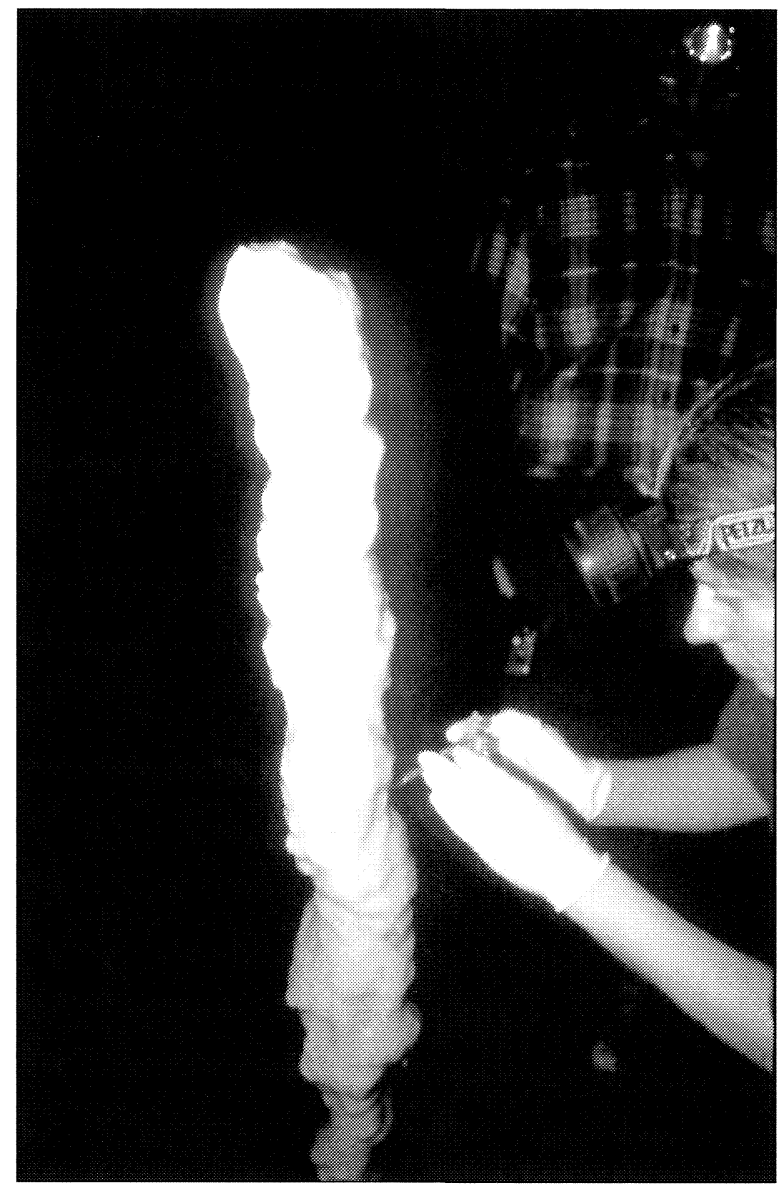

Lám. III. La Dra. Sabine Rölleke recogiendo muestras para el estudio de contaminación microbiológica en La Garma (Cantabria).

Es todavía pronto para valorar los resultados de estas mediciones. No obstante, como se puede ver en el ejemplo de la figura 2, referido a las temperaturas, se abren interesantes vías de trabajo. A pesar de la gran estabilidad general de las condiciones ambientales, se observan importantes diferencias entre los resultados obtenidos en las tres estaciones de control. En la del vestíbulo, las variaciones anuales son mucho más moderadas (del orden de $0,1^{\circ}$ entre el invierno y el verano, frente a $0,3^{\circ}$ en la zona central de la cueva y $0,6-0,7^{\circ}$ en el fondo), lo que refleja, sin duda, la existencia de una circulación del aire entre La GarmaA y el nivel hidrostático, dejando la antigua entrada al margen. Por otro lado, parece probable que el ritmo de renovación de las masas de aire sea bastante lento, a juzgar por el desfase temporal de varios meses entre las temperaturas máximas y mínimas atmosféricas en la región y las observadas en la Galería Inferior. En lo que se refiere a la influencia de la presencia humana, hasta ahora sólo se ha detectado en los valores de $\mathrm{CO}_{2}$ cuando los investigadores estaban durante un período relativamente largo cerca de la estación. No obstante, la permanencia en la cueva ha sido hasta ahora muy esporádica y en grupos muy pequeños, con lo que habrá que esperar al desarrollo de trabajos más continuados para valorar este aspecto adecuadamente.

Otra excelente posibilidad que ofrece La Garma es el estudio del desarrollo de la contaminación microbiológica en medios hipogeos. La ausencia de visitantes en más de un milenio en la Galería Inferior permite contrastar si las colonias de bacterias que pueblan en la actualidad las cuevas con arte rupestre se deben exclusivamente a factores antrópicos, o si, por el contrario, habitan estos lugares de forma natural. Con este objeto, los Dres. Cesáreo Saiz Jiménez, del Instituto de Recursos Naturales y Agrobiología del CSIC, y Sabine Rölleke (Universität Wien; Institut für Mikrobiologie und Genetik) han realizado un programa de muestreo en paredes de toda la cueva (Lám. III), cuyos resultados serán de la máxima importancia para la conservación del arte rupestre en esta y en otras cuevas.

Otro factor importante para la conservación de las pinturas rupestres es la propia composición de los colorantes, de gran interés también desde el punto de vista del comportamiento de las sociedades prehistóricas. La Garma ofrece también magníficas expectativas para este tipo de investigación, pues a la variedad aparente de coloraciones en las pinturas se une la existencia de restos de la preparación y la ejecución de los colorantes en el suelo de diversos lugares de la cueva. Por ello, uno de los más reputados especialistas en este tema, el Dr. Michel Menu, del Centre de Recherche et de Restauration des Musées de Fran$c e$, ha realizado un amplio muestreo en la Galería Inferior.

$\mathrm{Al}$ margen del control de las variables reseñadas anteriormente, el programa diseñado por el Dr. Hoyos incluye la caracterización petrológica y mineralógica de las rocas soportes de las representaciones, el análisis de los fenómenos de bioinducción en la dinámica de los microcristales superficiales de carbonatos, así como los procesos de alteración y reconstrucción de las paredes y techos de la cavidad, con el propósito de mejorar nuestro conocimiento acerca de su grado de estabili- 
dad y los potenciales efectos de tales procesos sobre las representaciones parietales.

\section{LA GARMA AL SERVICIO DE LA SOCIEDAD. PERSPECTIVAS PARA LA PUESTA EN VALOR DE UN CONJUNTO ARQUEOLÓGICO COMPLEJO}

Hasta hace no muchos años, en las enseñanzas impartidas en las universidades españolas se presentaba explícitamente -o al menos subyacía- la equiparación de Arqueología a excavación, y de excavación a destrucción; una línea argumental insostenible en una época en la que el Patrimonio Histórico y, por tanto, el Patrimonio Arqueológico, debe su consideración como tal a la acción social que cumple, y que tiene su retorno en una ciudadanía cada vez más abierta y receptiva, que demanda su derecho al conocimiento de los bienes que forman parte del legado colectivo.

El papel del arqueólogo -un privilegiado intermediario entre el pasado y el presente, en afortunada expresión de H. Carter (Carter y Mace, 1923)no se limita a la excavación, sino que incluye una cadena de actuaciones que comienzan con la decisión de intervenir tras un descubrimiento - programado o casual-, pasa por la excavación, la conservación, la protección, la recuperación de materiales y su estudio, y termina en la difusión de los resultados. La conservación, la publicación y la puesta en valor son elementos fundamentales e inexcusables, y así se recoge reiteradamente en las recomendaciones de organismos y conferencias internacionales, como la del ICCROM de Roma (1983), la del ICOMOS de Lausana (1990) o la Convención del Consejo de Europa para la protección del Patrimonio Arqueológico de Europa (Malta, 1992). Desde este punto de vista, las medidas de conservación deben estar previstas y presentes antes, durante y después de la intervención arqueológica (Price, 1987). En palabras de J.H. Stubbs (1987), la planificación de la conservación debe comenzar con el proyecto de intervención a corto y medio plazo.

El proyecto de investigación del Complejo Arqueológico de La Garma se enmarca -no podía ser de otra manera- en el espíritu de la normativa legal vigente (en particular la propia Constitución Española, la Ley 16/85 del Patrimonio Histórico Español y la Ley de Cantabria 11/1998 del Patrimonio Cultural de Cantabria) y de las recomendaciones de los organismos internacionales implicados en Edu- cación y Cultura. Todas estas normas y documentos establecen claramente la obligación de defender y conservar el Patrimonio Histórico, en función de la importante acción social que cumple. A este respecto, es interesante subrayar que la normativa española prevé una especial protección para el Patrimonio Arqueológico (muy probablemente por su particular fragilidad), al establecer el art. 44.1 de la Ley de Patrimonio Histórico Español el carácter de dominio público para los restos materiales del $\mathrm{Pa}$ trimonio Histórico descubiertos como consecuencia de excavaciones, remociones de tierra o por azar. De esta manera, los bienes del PatrimonioArqueológico gozan de un peculiar estatuto jurídico, en función de la imperiosa necesidad de su preservación para cumplir su función social, de manera que, siguiendo a Giannini, "la titularidad sobre la cosa queda en un segundo plano en beneficio de su valor cultural vocado al disfrute colectivo bajo la tutela jurídica de los poderes públicos" (Barcelona, 2000: 134-135).

En el caso concreto del Complejo Arqueológico de La Garma hay otros aspectos colaterales dignos de ser tenidos en cuenta.Aunque desde hace varios años se está produciendo un goteo constante de nuevas localizaciones de lugares con arte rupestre paleolítico (12), el descubrimiento de esta cueva despertó una justificada expectación por el excepcional estado de conservación de las pinturas y grabados y de su contexto inmediato (13).

No hay que olvidar que, como consecuencia del impacto del hallazgo y posterior autentificación de Altamira, el mundo del arte prehistórico ha tenido y tiene una fuerte presencia en Cantabria, tanto en la trayectoria de las investigaciones arqueológi-

(12) En los últimos 20 años, casi se ha doblado el número de conjuntos con arte rupestre paleolítico en la región Cantábrica. En el catálogo de González Echegaray (1978) se incluían 55, por 86 en 1994 (González Echegaray y González Sainz, 1994) y 92 seguros en la actualidad (González Sainz y Moure, 2000).

(13) La noticia del descubrimiento tuvo un gran impacto en los medios de comunicación; ocupó lugares centrales en las portadas de los diarios regionales, con titulares que hacían referencia, sintomáticamente, al descubrimiento "de una segunda Altamira", y se recogió ampliamente en la prensa nacional, en radio y televisión. Fue también considerable el impacto en publicaciones periódicas, tanto de divulgación científica como de información general (National Geographic, Muy Interesante, Ciencia y Vida, El Semanal, Antena Semanal...) Tras el boom inicial, La Garma ha seguido siendo una referencia constante en la prensa regional, en la que ha sido objeto de noticias explícitas al menos en 74 días entre 1995 y 1999 , cinco de ellos en primera página. En cuanto a su difusión nacional, ha merecido el interés de relevantes medios audiovisuales (Radio Televisión Española, Antena 3 TV, Tele 5) e impresos como El Cultural y El País Semanal, que le han dedicado sendos reportajes. 


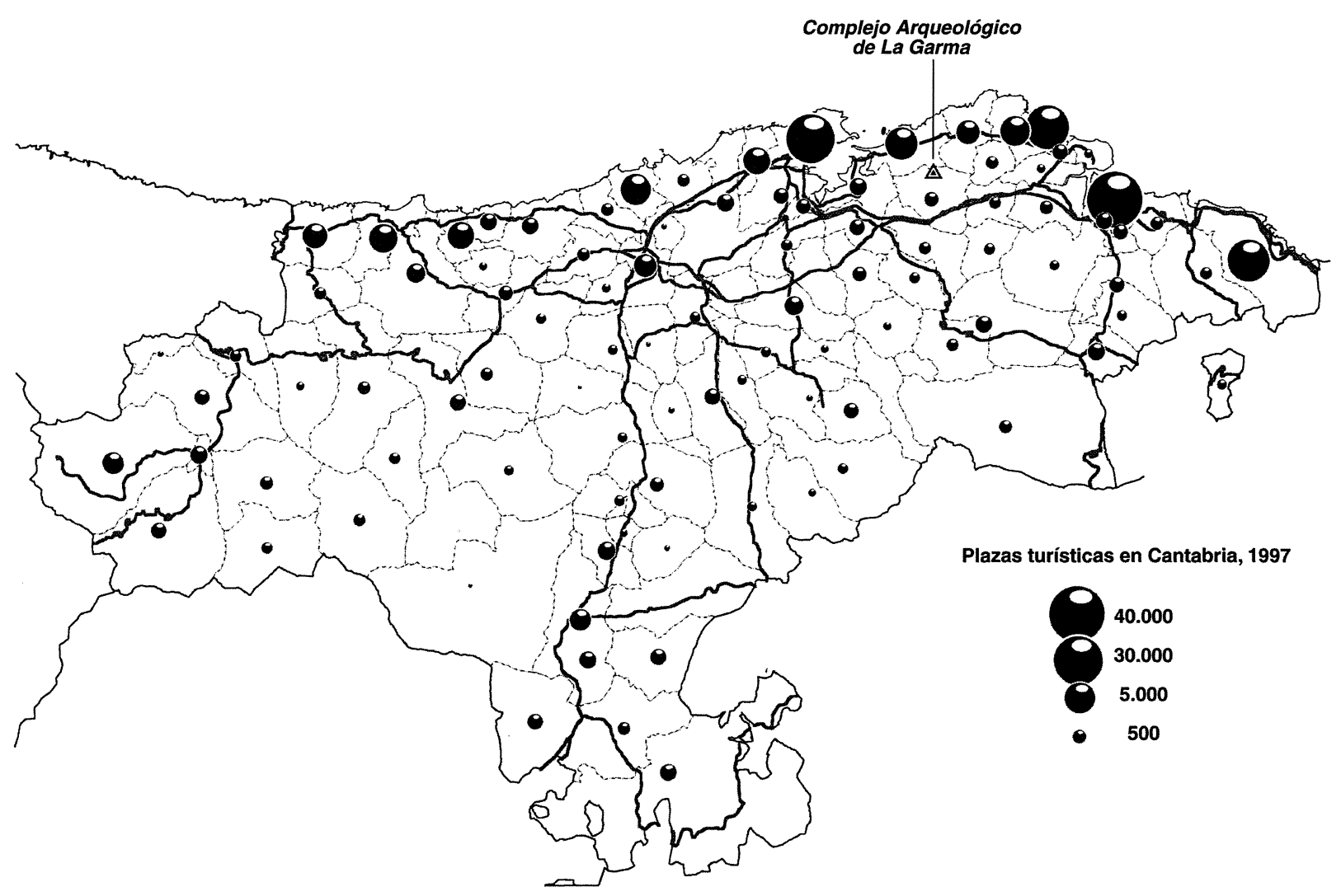

Fig. 3. Situación de La Garma en relación con las principales vías de comunicación y las infraestructuras turísticas de la región. Los símbolos representan el número de plazas en hoteles, segundas residencias y campings, por municipios (según García Codrón et alii, 1999: 238).

cas (Moure, 1995) como en la sociedad en su conjunto. Los bisontes y el nombre de la, en palabras de Rafael Alberti, "oquedad pintada más asombrosa del mundo" ocupan un papel protagonista en la iconografía regional, y se repiten en todo tipo de empresas, publicaciones y productos dentro y fuera de la Comunidad Autónoma. Además, el proyecto de reproducción de Altamira ha despertado grandes expectativas en una región que ve en la puesta en valor de su patrimonio natural y cultural una alternativa económica a su evidente declive industrial y al carácter estacional de su turismo actual. El lema promocional Cantabria Gran Reser$v a$, cuyo logotipo incorpora -cómo no- la recreación de un bisonte de Altamira, resulta muy elocuente en este sentido.

A este respecto, conviene tener en cuenta que $\mathrm{La}$ Garma se sitúa en una comarca en la que el turismo tiene una gran incidencia económica. A la crisis de los sectores económicos tradicionales de la zona (ganadería, pesca, algunas industrias) se le une una intensa y creciente presión urbanística, en particular desde la apertura en 1995 de la autopista A-8, que ha favorecido la expansión de las instalaciones turísticas y las segundas residencias por toda la comarca de Trasmiera (Fig. 3). La notable mejora de las comunicaciones que supuso esta vía ha contribuido en particular a la expansión inmobiliaria orientada al mercado vasco (muy en particular bilbaíno) que, desde su tradicional ocupación de la costa oriental hasta el área del cabo de Ajo, se ha expandido hasta la propia bahía de Santander. La zona donde se sitúa La Garma, a sólo $6 \mathrm{~km}$ de la mencionada autopista, $25 \mathrm{~km}$ de Santander y 75 de Bilbao, está inmersa en ese cambio económico. De hecho, en los días en que se escriben estas líneas se anuncian promociones urbanísticas promovidas por empresas vizcaínas que pretenden construir centenares de chalets a sólo un par de kilómetros de $\mathrm{La}$ Garma. 
En este contexto, el macizo de La Garma presenta una serie de particularidades relevantes. En primer lugar, constituye un recurso cultural de indudable atractivo para el público, susceptible de convertirse en un foco de atracción turística, por lo menos en la mente de gran parte de la ciudadanía cántabra, educada en la tradición de las grandes cuevas abiertas al turismo masivo, al estilo de las Altamira y El Castillo de otros tiempos. Por otro lado, pese a estar en una comarca intensamente humanizada, La Garma y su entorno conservan uno de los mejores restos de bosque autóctono de la comarca, y una apariencia general bastante rural, lo que indudablemente mejora las perspectivas del conjunto como recurso turístico.

Por lo tanto, como comentábamos más arriba, la investigación de La Garma no puede ni debe plantearse desde una "inocente" perspectiva meramente académica. Hemos de ser conscientes del contexto social en que nos movemos: una sociedad que nos observa, nos financia, se crea expectativas más o menos realistas... Desde este punto de vista, la llamada "puesta en valor" de La Garma es un aspecto de gran importancia en el conjunto del proyecto. Yacimientos tan relevantes como éste pueden convertirse en un elemento dinamizador de la región donde se localizan, tanto desde el punto de vista educativo y cultural como, ¿por qué no?, del económico (Borrell et alii, 1996). No obstante, nuestra perspectiva es que, en este caso se deben evitar las prisas. No es posible desarrollar una correcta política de puesta en valor de un bien cultural sin conocerlo a fondo, y el conocimiento de La Garma ha de ser un proceso lento y complejo, al menos si se pretende preservar adecuadamente el conjunto. Por ello, en la fase en que nos encontramos actualmente, creemos que es fundamental dar prioridad absoluta a la conservación y a la investigación.

De todas formas, con las limitaciones que impone el carácter preliminar e incompleto de nuestros trabajos, se ha realizado un importante esfuerzo de divulgación, de dar a conocer, siquiera provisionalmente, los rasgos fundamentales de La Garma a diversos planos de esa sociedad expectante. Los coordinadores del proyecto, en ocasiones con otros colaboradores, han publicado al respecto diversos trabajos que pueden clasificarse en tres categorías fundamentales, según su orientación más o menos generalista y el público al que están dirigidos: panoramas globales del complejo arqueológico o "estados de la investigación" (Arias et alii 1996c, 1997b, 1999b; Arias 1999), artículos específicos acerca de algunos aspectos concretos (Arias et alii, 1996a; González Sainz, 1999; Arias et alii, 1999; Pereda, 1999), y descripciones profusamente ilustradas en revistas de divulgación (Arias et alii, 1996b, 1997a, 1999a).

Otro aspecto fundamental en el capítulo de difusión del Complejo Arqueológico de La Garma lo constituyen las numerosas conferencias impartidas por los coordinadores del proyecto de investigación en el ámbito regional, nacional e internacional, entre las que destacan la organizada por el Gobierno de Cantabria en el Palacio de Festivales de Santander (1995), dos seminarios en el Musée de l'Homme de París (1996 y 1999) y la edición de 1999 de la conferencia Rudolf Virchow, organizada en Neuwied (Renania-Palatinado) por el $R \ddot{o}$ misch-Germanisches Zentralmuseum y la Fundación Prinz Maximilian zu Wied.

No obstańte, a fines de 1998 se entendió que la información acerca de La Garma estaba quedando, tal vez, demasiado circunscrita a los círculos científicos. Con objeto de subsanar esta circunstancia, en los meses de mayo y junio de 1999 se desarrolló un proyecto específico de divulgación, gracias a un convenio entre la Universidad y el Gobierno Regional de Cantabria. El programa de actividades se organizó en dos apartados complementarios: una exposición temporal (Lám. IV), desarrollada en la Sala "Luz Norte", de la Consejería de Cultura y Deporte del Gobierno de Cantabria, entre los días 12 de mayo y 12 de junio de 1999, y un ciclo de conferencias sobre arte paleolítico europeo, que reunió, junto a los coordinadores del Proyecto, a algunos de los más relevantes investigadores de esa materia: los profesores Gerhard Bosinski, Rodrigo de Balbín Behrmann, Joaquín González Echegaray y Denis Vialou.

¿Cuáles son las perspectivas a medio o largo plazo de poner el espacio físico de La Garma a disposición de la sociedad? (evidentemente, los conocimientos que se generen en la investigación siempre lo estarán). Insistimos en que es pronto para hacer una planificación realista. No obstante, creemos que se pueden apuntar ya unas primeras líneas maestras que pueden orientar la acción futura.

Parece evidente que, individualmente considerados, los yacimientos que integran este Complejo protegido bajo la figura legal de Zona Arqueológica tienen viabilidad y posibilidades de disfrute masivo muy desiguales: desde las muy elevadas de los sitios al aire libre (el castro, las entradas a $\mathrm{La}$ 


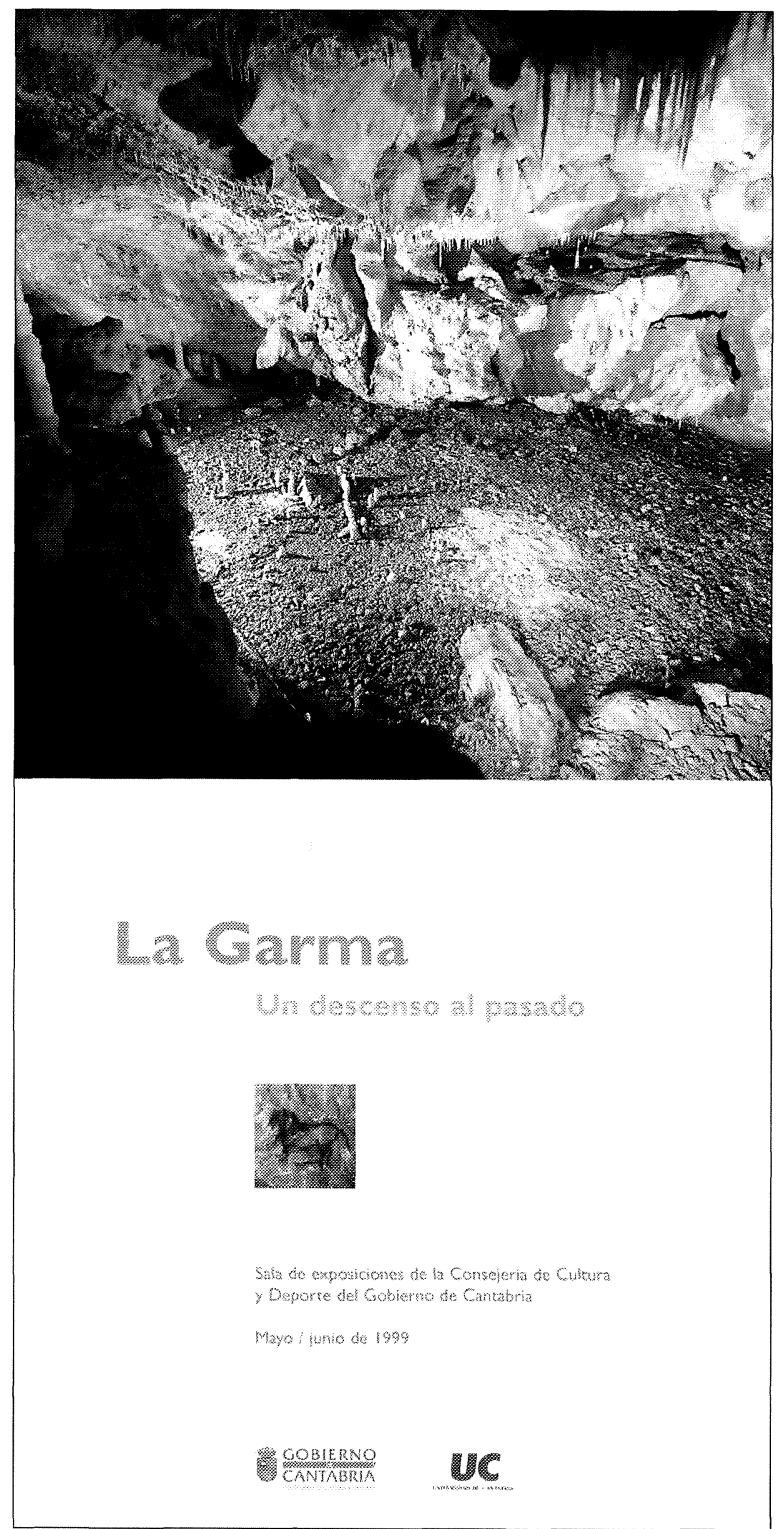

Lám. IV. Cartel anunciador de la exposición sobre La Garma (Cantabria) celebrada en Santander en mayo y junio de 1999.

Garma A, La Garma B, la cueva del Mar, etc.) hasta muy reducidas en el caso de la Galería Inferior. En cualquier caso, como señalan repetidamente las recomendaciones a este respecto de organismos internacionales, las acciones prioritarias han de ser la protección (evitar el deterioro o la degradación tras su descubrimiento, durante las intervenciones arqueológicas y después de ellas) y la investigación, puesto que difícilmente podrá difundirse de forma rigurosa aquello que no está estudiado.
Desde ese punto de vista, es innegable que las galerías interiores de La Garma (Galería Intermedia y Galería Inferior) resultan totalmente incompatibles con un turismo masivo. Por un lado, existen serias dificultades de acceso y seguridad (pasos estrechos, dificultades de tránsito, descenso de dos peligrosas simas) y, por otro, la conservación de su medio natural y de las evidencias arqueológicas que contiene sólo es posible si se limita la entrada a grupos muy reducidos de personas entrenadas, y siempre bajo un riguroso seguimiento de su presencia.

Desde un principio el Gobierno de Cantabria se ha mostrado sensible a las recomendaciones del equipo investigador, y en ningún caso se han planteado eventuales intervenciones agresivas, que tan nefastas (y muchas veces irreversibles) consecuencias han tenido en otras cuevas prehistóricas. Por mencionar uno de los muchos errores cometidos en la cueva de Tito Bustillo (Ribadesella, Asturias), la apertura de la entrada original de la Galería Inferior de La Garma, además de no solucionar el acceso al resto de la galería, supondría la destrucción inmediata del yacimiento conservado en superficie y consecuencias imprevisibles en la conservación de las pinturas rupestres, en particular las de la zona del vestíbulo.

Todas las partes implicadas -administración, arqueólogos, organismos investigadores y académicos, sociedad en su conjunto- tenemos una grata pero difícil responsabilidad histórica: gestionar adecuadamente un sitio tan trascendente como La Garma. Ahora bien, esto no implica que La Garma tenga que convertirse necesariamente en una especie de reserva cerrada al público general. La imposibilidad de compatibilizar gestión responsable de los recursos culturales y turismo masivo en la Galería Inferior no excluye alternativas a un uso radicalmente restrictivo del monte de La Garma en su conjunto. Si algo distingue a esta afortunada colina es precisamente la enorme variedad de recursos arqueológicos que almacena, tanto desde el punto de vista de los tipos de yacimientos como desde el de las épocas representadas. La cuestión estriba, por lo tanto, en una adecuada planificación de qué se quiere transmitir al público (a los variados públicos) que pueda verse atraído por este lugar, y de cómo se ha de mostrar, cuestión nada fácil, pero que ocupa un lugar cada vez más relevante en la Arqueología contemporánea (Ruiz Zapatero, 1998). En el caso del monte de La Garma, creemos fuera de toda duda que, con una infraestructura y 
un respaldo didáctico adecuados, la Zona Arqueológica puede y debe superar la superada noción de "cueva con pinturas" para convertirse en una oferta cultural que permita visitar y comprender yacimientos de diferentes tipos y épocas: cuevas de hábitat, cuevas sepulcrales, concheros y, muy particularmente, un magnífico castro con un emplazamiento estratégico desde el que se domina la bahía de Santander y un buen tramo del litoral de Cantabria.

En resumen, La Garma es un lugar amplio, bien comunicado, cercano a núcleos de población importantes y en el que se concentra una amplísima muestra de yacimientos arqueológicos. No es desdeñable, en este contexto, la alta calidad paisajística y medioambiental de su entorno. Como señalábamos más arriba, La Garma conserva una de las pocas masas de bosque autóctono existentes en una comarca en que ha sido sustituido masivamente por pradería o por cultivos forestales, y domina uno de los valles que mejor mantienen el ambiente rural de esta parte de la región. Esta feliz confluencia de circunstancias abre unas excelentes perspectivas desde el punto de vista educativo y desde el del mero ocio. A este respecto, es fácil comprobar que La Garma cumple estrictamente los elementos diagnósticos que definen un Parque Arqueológico (Querol, 1993).

Desde nuestro punto de vista, la política más aconsejable con respecto a la Galería Inferior debería primar por encima de toda otra consideración la conservación de ese privilegiado espacio en un estado lo más cercano posible al del momento del descubrimiento. Esto implica que el acceso público debería canalizarse a través de posibilidades no agresivas para la riqueza arqueológica de la Galería, y siempre avaladas por los estudios técnicos pertinentes. A este respecto, creemos que se deben explorar exhaustivamente las posibilidades que abren las nuevas tecnologías para conocer adecuadamente el lugar sin necesidad de presencia física de grandes masas de visitantes. De todas maneras, en un caso tan excepcional como La Garma, cualquier precaución es poca. Todas las decisiones que se tomen deben apoyarse en estudios exhaustivos, y evitar en la medida de lo posible la irreversibilidad de sus consecuencias. La historia de la gestión de los recursos arqueológicos (con casos como los de Lascaux y Altamira como más destacados) nos pueden dar numerosas pautas de los caminos que debemos evitar en el futuro.

\section{BIBLIOGRAFÍA}

Arias CABAL, P. (1999): “La Garma (Kantabrien/Spanien): Eiszeitliche Wandkunst und Wohnplätze in einer verschlossenen Höhle". Jahrbuch des Römisch-Germanischen Zentralmuseums, 46: 3-20.

Arias Cabal, P.; González Sainz, C.; Moure Romanillo, A. y ONTAÑón PEREdo, R. (1996a): “L'art pariétal paléolithique du complexe archéologique de La Garma (Omoño, Cantabria, Espagne).Approche préliminaire/ Palaeolithic rock art in La Garma Archaeological Complex (Omoño, Spain). A preliminary approach". International Newsletter on Rock Art, 14: 1-5.

- (1996b): "La Garma. Un nuevo complejo arqueológico con arte rupestre en Cantabria". Revista de Arqueología, XVII, 188: 8-17.

- (1996c): "El complejo arqueológico de La Garma (Omoño, Ribamontán al Monte). Primera aproximación”. En J.A. García de Cortázar (ed.): La memoria histórica de Cantabria. Servicio de Publicaciones de la Universidad de Cantabria-Asamblea Regional de Cantabria. Santander: 245-258.

- (1997a): "La cueva de La Garma". Historia 16, XXII, 260: 96-105.

- (1997b): "El proyecto «Estudio integral del complejo arqueológico de La Garma (Omoño, Cantabria)». Primeros resultados". En R. de Balbín Behrmann y P. Bueno Ramírez (eds.): II Congreso de Arqueología Peninsular. Tomo I. Paleolítico y Epipaleolítico:147-162. Fundación Rei Afonso Henriques. Zamora.

- (1999a): "La Garma, testigo excepcional de la Prehistoria". La Aventura de la Historia, 7: 68-77.

- (1999b): La Garma: Un descenso al pasado. Consejería de Cultura y Deporte del Gobierno de Cantabria. Santander.

Arias Cabal, P.; Ontañón Peredo, R.; González UrquiJo, J.E. e IbÁÑ̃z Estévez, J.J. (1999): "El puñal de sílex calcolítico de La GarmaA (Omoño, Cantabria)". Sautuola VI. Estudios en homenaje al profesor Dr. García Guinea. Consejería de Cultura y Deporte del Gobierno de Cantabria. Santander: 219-228.

BARCELONA LlOP, J. (2000): "El dominio público arqueológico".Revista deAdministración Pública, 151: 133-165.

Borrell, M.; Bosch, J. y CARreté, J.M. (1996): "Els conjunts patrimonials com a elements generadors de recursos". En P. González Marcén (ed.): Actes del seminari Arqueologia $i$ ensenyament. 12-14 de setembre de 1996: 198-209. Departament d'Antropologia Social i de Prehistòria de la Universitat Autònoma de Barcelona. Bellaterra.

BRunet, J.; Vidal, P. y Vouvé, J. (1990): "La conservation de Lascaux". En Lascaux. Le premier chef d'oeuvre de l'Humanité. Faton (Les Dossiers d'Archèologie 152). Quétigny: 68-75.

BRUNET, J. y VouvÉ, J. (dirs.) (1996): La conservation des grottes ornées. Éditions du CNRS. Paris. 
Carter, H. y Mace, A.C. (1923): The tomb of Tut.ankh. Amen, discovered by the late Earl of Carnavon and Howard Carter. Cassell. London.

Cleere, H. (ed.) (1984): Approaches to the Archaeological heritage. Cambridge University Press. Cambridge.

ForTEA PÉREZ, J. (ed.) (1993): La protección y conservación delArte rupestre paleolítico. Mesa redonda Hispanofrancesa. Colombres (Asturias). 2 al 6 de Junio de 1991. Servicio de Publicaciones del Principado de Asturias. Oviedo.

García Codrón, J.C.; De Meer, A.; Martín Latorre, E.; De la Puente, L. y Reques, P. (1999): "Cantabria". La España de las Autonomías. Síntesis. Madrid: $217-$ 244.

GonZÁlEZ EchEGARAY, J. (1978): "Cuevas con arte rupestre en la región cantábrica". Curso de arte rupestre paleolítico. UIMP. Zaragoza: 49-77.

GonzÁlez Echegaray, J. y GonZÁlez Sainz, C. (1994): "Conjuntos rupestres paleolíticos de la cornisa cantábrica". Complutum, 5: 21-43

GonZÁlez SAINZ, C. (1999): "El Megaceros giganteus en la región cantábrica: Las representaciones parietales de las cuevas de La Pasiega y La Garma". Sautuola VI. Estudios en homenaje al profesor Dr. García Guinea. Consejería de Cultura y Deporte del Gobierno de Cantabria. Santander: 185-195.

GonzÁlez Sainz, C. y Moure Romanillo, A. (2000): "La investigación reciente del arte paleolítico de la región cantábrica. Apuntes para un 'estado de la cuestión" ". Actas do $3 .^{\circ}$ Congresso de Arqueologia Peninsular, II. Paleolítico da Península Ibérica: 475-492. ADECAP. Porto.

McManamon, F.P. (2000): "Archaeological messages and messengers". Public Archaeology, 1: 5-20.

Moure Romanillo, A. (1995): "Prehistoria de Cantabria: Más de un siglo de historiografía y bibliografía". En M. Suárez Cortina (ed.): Historia de Cantabria: Un siglo de historiografía y bibliografía (1900-1994). Fundación Marcelino Botín. Santander, I: 37-68.
Pereda SaIz, E. (1999): "ElAlto de La Garma: un castro de la Edad del Hierro en el Bajo Miera". En J.M. Iglesias y J.A. Muñiz (eds.): Regio Cantabrorum. Caja Cantabria. Santander: 63-77.

Price, N.P.S. (ed.) (1987): La conservación en excavaciones arqueológicas. ICCROM-Ministerio de Cultura. Madrid.

Querol FernÁndez, M.A. (1993): "Filosofía y concepto de Parque Arqueológico". En Seminario de Parques Arqueológicos (Madrid, 1989): 11-22. Ministerio de Cultura. Madrid.

ROMERO CABOT, R. (1997): “Arte rupestre y conservación”. Extremadura Arqueológica, VII: 23-32.

Ruiz ZaPATERo, G. (1998): "Fragmentos del pasado: la presentación de sitios arqueológicos y la función social de la Arqueología”. En P. González Marcén (ed.): Actes del II seminari Arqueologia i ensenyament. 12-14 de novembre de 1998: 7-34. Departament d'Antropologia Social i de Prehistòria de la Universitat Autònoma de Barcelona. Bellaterra.

SChadla-Hall, T. (1999): "Editorial: Public Archaeology". European Journal of Archaeology, 2/2: 147-158.

SiERRA, L. (1909): "Notas para el mapa paleoetnográfico de la Provincia de Santander". En Actas y Memorias del

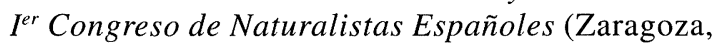
1908): 103-117. Madrid.

StubBs, J.H. (1987): "Protección y exhibición de estructuras excavadas”. En N.P.S. Price (ed.): La conservación en excavaciones arqueológicas. ICCROM-Ministerio de Cultura. Madrid: 85-101.

VV.AA. (1983): Estudios físico-químicos sobre la cueva de Altamira. Ministerio de Cultura. Madrid.

VV.AA. (1984): Cueva deAltamira: Estudios físico-químicos de la Sala de Policromos. Influencia de la presenciăhumana y criterios de conservación. Ministerio de Cultura. Madrid.

WILLEMS, W.J.H. (1998): "Archaeology and heritage management in Europe: trends and development". European Journal of Archaeology, 1/3: 293-311.

T. P., 57, n. $^{\circ} 2,2000$ 